\title{
Expanded use of rituximab in the management of non-Hodgkin lymphoma
}

This article was published in the following Dove Press journal:

OncoTargets and Therapy

30 July 2009

Number of times this article has been viewed

\author{
Dennis A Eichenauer' \\ Andreas Engert ${ }^{\prime}$ \\ Holger Schulz ${ }^{2}$ \\ 'First Department of Internal \\ Medicine, University Hospital \\ Cologne, Cologne, Germany; \\ ${ }^{2}$ pioh - Praxis Internistischer \\ Onkologie und Häematologie \\ Kölnerstr. g, Frechen, Germany
}

Correspondence: Holger Schulz pioh - Praxis Internistischer Onkologie und Häematologie Kölnerstr. g, 50226, Frechen, Germany

Tel +49 02234-99959-0

Fax +49 02234-99959-25

Email hschulz@pioh.de

\begin{abstract}
Rituximab is a chimeric monoclonal antibody targeting the B cell antigen CD20. Since its first approval for clinical use in 1997, rituximab has become an inherent part of the treatment of CD20-positive lymphoma. In previously untreated non-Hodgkin lymphoma (NHL) conventional chemotherapy supplemented by rituximab (R-chemotherapy) was shown to be more effective than chemotherapy alone. This holds true for indolent as well as aggressive NHL. Rituximab was also shown to be beneficial when used as maintenance therapy or part of salvage and re-induction regimens in relapsed NHL. Administration of rituximab is generally well tolerated. The most common side effects including fever, urticaria and bronchospasm are mostly mild, treatable and restricted to the infusion period. Thus, rituximab can usually be administered in an outpatient setting. Due to its favorable effect/side effect ratio, clinical trials are currently evaluating a possible role for rituximab in several other diseases such as Hodgkin lymphoma (HL) and non-malignant autoimmune disorders. This review aims at giving an overview of the pharmacological properties of rituximab and summarizing key publications and recent literature on its use in NHL.
\end{abstract}

Keywords: rituximab, non-Hodgkin lymphoma, immunochemotherapy

\section{Introduction}

Non-Hodgkin lymphoma (NHL) has been classified into two types: aggressive (ie, fast growing) and indolent (ie, slow growing). ${ }^{1}$ Aggressive NHL such as the most common NHL subtype diffuse large B cell lymphoma (DLBCL) are characterized by a rapid tumor growth resulting in death of patients after a few weeks to months if untreated. Thus, treatment must be initiated immediately after diagnosis. However, patients with aggressive NHL can potentially be cured with an appropriate multi-agent chemotherapy. ${ }^{2}$ In contrast, indolent NHL such as follicular lymphoma (FL) are mostly incurable and patients are commonly in a palliative situation. Here, only a small portion of patients diagnosed at an early stage achieve long-term disease-free survival by radiotherapy and can be considered cured. ${ }^{3}$ In the vast majority of patients with indolent NHL, disease is diagnosed at an advanced stage. In these patients treatment is not indicated until disease becomes symptomatic since no survival benefit for patients undergoing early treatment compared to patients pursuing a watch-and-wait strategy has been shown to date. ${ }^{4}$ When disease becomes symptomatic and treatment is applied, patients with indolent NHL usually show good response to first-line therapy. Unfortunately, there are only few long-term survivors. The median survival is 8 to 10 years. ${ }^{5}$

In the past decade treatment of NHL and particularly of B cell NHL, which represents $85 \%$ to $90 \%$ of all NHL cases, has improved significantly, ${ }^{6}$ mainly because 
of the advent of antibody-based immunotherapy and its implementation in NHL treatment protocols.

The immunotherapeutic agent most widely used is the anti-CD20 antibody rituximab. Since its first approval for clinical use in 1997, indications for rituximab in lymphoma treatment expanded fundamentally so that current B cell lymphoma therapy is inconceivable without rituximab.

\section{Rituximab}

Rituximab is a chimeric monoclonal antibody directed against the surface antigen CD20. CD20 is expressed on nearly all malignant and mature B cells but, importantly, not on plasma cells, precursor B cells and stem cells. ${ }^{7}$ Rituximab is composed of murine variable regions linked to a human Fc component. ${ }^{8}$ Various effects such as complement-dependent lysis, effector cell-mediated lysis, induction of apoptosis, direct growth arrest and sensitization to conventional chemotherapy were observed upon CD20 binding of rituximab and contribute to the antibody's activity. ${ }^{8-10}$

Since CD20 is not internalized or shed from the cell surface and does not circulate in the plasma, anti-CD20 antibodybased immunotherapy was soon regarded as a promising tool in the treatment of B cell NHL, and consequently the first clinical trials evaluating safety and efficacy of rituximab were started in the early 1990s. ${ }^{7,11}$ These trials resulted in the antibody's approval for the treatment of relapsed and refractory low-grade or follicular CD20-positive NHL in 1997. ${ }^{12-14}$ Since then the number of indications for the use of rituximab has risen steadily, and now rituximab is an essential part in the treatment of patients with CD20-positive NHL.

When used as single agent, rituximab is commonly administered at the standard dose of $375 \mathrm{mg} / \mathrm{m}^{2}$ iv once weekly for four doses. However, the optimal dose has never been defined precisely in clinical trials. The dose of $375 \mathrm{mg} / \mathrm{m}^{2}$ administered weekly was chosen as standard for further testing on the basis of pharmacokinetic and pharmacodynamic data. In addition, this dose could be given safely and effectively in an outpatient setting. ${ }^{14}$ Serum analyses showed a median serum half-life for rituximab of 76.3 hours after the first infusion and 205.8 hours after the fourth infusion. This increase in serum half-life is mainly due to a decrease of the rituximab clearance from the first to the fourth infusion. ${ }^{15}$ Depletion of B cells was shown to occur within the first three doses and to persist for about 6 to 9 months. B cell count was found to be recovered about 12 months after completion of treatment. ${ }^{13}$

Despite the high activity of rituximab, novel anti-CD20 antibodies such as the fully human antibody ofatumumab and the humanized antibody veltuzumab (hA20) were developed with the purpose of further improving anti-CD20 immunotherapy. ${ }^{16,17}$ These antibodies might have a higher efficacy than rituximab due to improved pharmacological and binding properties and less side effects based on a reduced immunogenicity. They are being evaluated in phase I/II clinical trials and first data were recently published. ${ }^{18}$

\section{Clinical trials with rituximab in indolent and mantle cell lymphoma}

Based on the results of phase I/II clinical trials conducted in the early 1990s, rituximab was approved for clinical use in lymphoma therapy in 1997. Two publications in particular ${ }^{12,13}$ played a pivotal role and paved the way for the extensive clinical use of rituximab.

First, a phase I dose-escalation trial mainly including patients with relapsed indolent lymphoma was carried out. Patients were treated with four weekly infusions of rituximab at a dosage of 125,250 or $375 \mathrm{mg} / \mathrm{m}^{2} .{ }^{12}$ Since no dose-limiting toxicities were observed and pharmacokinetic and pharmacodynamic data were considered optimal at $375 \mathrm{mg} / \mathrm{m}^{2}$, this dose was selected for further testing of single-agent activity in a phase II trial. In this phase II trial, 37 low-grade or FL patients with one to five prior lines of treatment received 4-weekly infusions of rituximab at $375 \mathrm{mg} / \mathrm{m}^{2}$. Remissions were observed in 50\% (17 patients) of evaluable patients with 9\% (3 patients) achieving complete remission (CR) and 41\% (14 patients) achieving partial remission (PR). An additional 8 patients (24\%) showed a tumor reduction of more than $20 \%$ but did not qualify as responders. Median time to progression was 10.2 months. Among the patients included, those with follicular small cleaved histology had the best response rate, with 13 of 21 achieving either CR or PR. Side effects of therapy were mostly mild, only 6 patients experiencing grade III or IV adverse events. The adverse events most commonly observed were fever, chills and nausea. ${ }^{13}$ After this trial had proven the single-agent activity of rituximab even in relapsed and heavily pre-treated low-grade NHL patients, several groups started evaluating combinations of rituximab and conventional chemotherapy in NHL patients.

For years the cyclophosphamide/doxorubicin/vincristine/ prednisone (CHOP) scheme was considered standard first-line treatment for the majority of NHL entities. After single-agent activity of rituximab had been demonstrated, the need became obvious to evaluate whether a combination of $\mathrm{CHOP}$ and rituximab might improve the results achieved with CHOP alone. After phase II trials had shown safety, feasibility and activity of rituximab-CHOP (R-CHOP), the German Low-Grade Lymphoma Study Group (GLSG) conducted a randomized trial 
including 428 previously untreated FL patients in advanced stages. ${ }^{19}$ Patients either received 6 to eight 8 of CHOP alone or 6 to 8 cycles of R-CHOP. Results showed a significant superiority for the combination. Overall response rate (ORR) was $96 \%$ in the R-CHOP arm compared to $90 \%$ in the CHOP $\operatorname{arm}(\mathrm{p}=0.011)$. CR was observed in $17 \%$ and $20 \%$, and PR in $73 \%$ and $77 \%$ of patients treated with CHOP and R-CHOP, respectively. Addition of rituximab also prolonged duration of remission. With a median follow-up of 18 months, only 28 of 233 patients in the R-CHOP arm experienced treatment failure compared to 61 of 205 patients in the CHOP arm ( $p<0.001)$. Median overall survival (OS) was not reached in both groups. However, at 3 years there were 6 deaths in the R-CHOP and 17 deaths in the CHOP group $(\mathrm{p}=0.016)$, which also indicates the superiority of the rituximab-containing therapy. Since the number of adverse events was comparable in both treatment arms, a significant superiority of R-CHOP over CHOP alone was the major result of this trial. ${ }^{20}$

Other clinical studies also showed the combination of rituximab with conventional chemotherapy to be more effective than chemotherapy alone. Salles et al compared 96 patients receiving 12 cycles of the cyclophosphamide/ adriamycin/etoposide/prednisolone (CHVP) plus interferonalpha over 18 months with 89 patients receiving 6 cycles of the same chemotherapy combined with 6 applications of the standard dose of rituximab and interferon-alpha over 18 months. All patients had advanced-stage FL and a high tumor burden. With a median follow-up of 5 years, patients receiving the rituximab-containing therapy had a significantly superior outcome. Event-free survival (EFS) estimates were $37 \%$ in the standard arm without rituximab and $53 \%$ in the rituximab-containing arm $(\mathrm{p}=0.001)$. OS did not differ significantly between treatment arms. Here, only a trend towards better OS in patients receiving the rituximab combination was detectable. ${ }^{21}$

Another randomized phase III study comparing 162 patients with advanced FL treated with cyclophosphamide/vincristine/ prednisone (CVP) alone with 159 patients treated with R-CVP also showed superior results for the rituximab combination. Patients randomized into the rituximab-containing arm had an improved outcome for all tested endpoints. ORR were $57 \%$ and $81 \%$ with CR rates of $10 \%$ and $41 \%$ in the CVP and the R-CVP arm, respectively ( $\mathrm{p}<0.0001$ ). Time to treatment failure (TTF) and time to progression (TTP) were significantly longer in the patient group treated with R-CVP ( $p<0.0001)$. With a median follow-up of 53 months, OS was also significantly superior in the R-CVP than the CVP $\operatorname{arm}(83 \%$ vs $77 \%, \mathrm{p}=0.029){ }^{22}$

Results of these trials were confirmed by a meta-analysis performed by the Cochrane Haematological Malignancies Group (CHMG). Data from 1943 patients from 7 randomized trials ( 5 including untreated and 2 including relapsed or refractory patients) comparing R-chemotherapy with chemotherapy alone in patients with FL, mantle cell lymphoma (MCL) and other indolent lymphoma were analyzed. R-chemotherapy was shown to lead to superior OS, response rates and disease control in comparison with chemotherapy alone. This held particularly true for the subgroups FL and MCL (Figures 1 and 2). ${ }^{23}$

To challenge the standard regimen for many indolent NHL, R-CHOP, the Study Group Indolent Lymphomas (StiL) conducted a randomized phase III trial with 439 patients

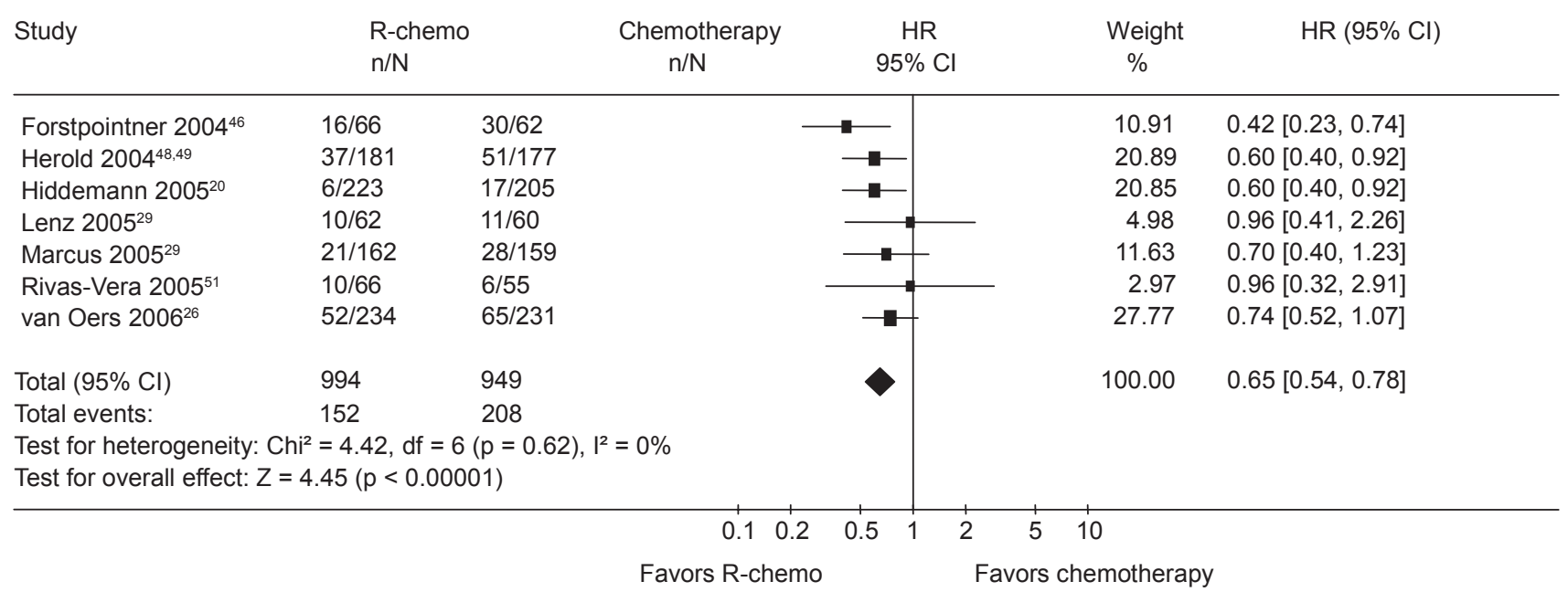

Figure I Overall survival for all patients with indolent or mantle cell lymphoma who received rituximab with chemotherapy (R-chemo) or chemotherapy alone. Reproduced with permission from Schulz H, Bohlius JF, Trelle S, et al. Immunochemotherapy with rituximab and overall survival in patients with indolent or mantle cell lymphoma: a systematic review and meta-analysis. J Natl Cancer Inst. 2007;99(9):706-714.44 Copyright @ 2007 Oxford University Press. 


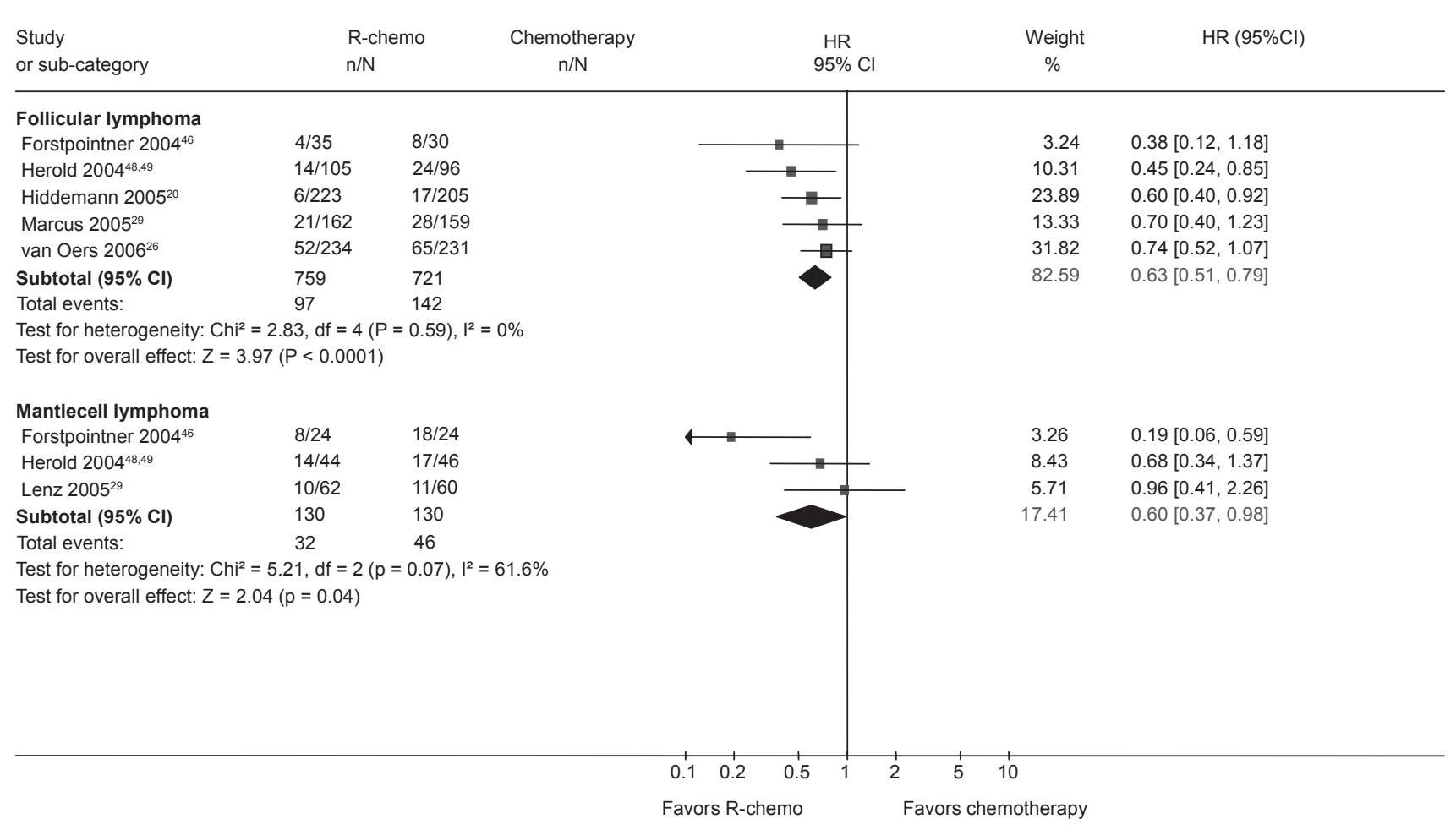

Figure 2 Overall survival for the subgroups of patients with indolent or mantle cell lymphoma who received rituximab with chemotherapy (R-chemo) or chemotherapy alone. Reproduced with permission from Schulz H, Bohlius JF, Trelle S, et al. Immunochemotherapy with rituximab and overall survival in patients with indolent or mantle cell lymphoma: a systematic review and meta-analysis. J Natl Cancer Inst. 2007;99(9):706-714. ${ }^{44}$ Copyright @ 2007 Oxford University Press.

in which R-CHOP was compared with bendamustine and rituximab (BR). Previous phase II trials had shown BR to have promising activity in indolent NHL. ${ }^{24}$ An interim analysis presented in 2007 revealed similar ORR and CR rates in the R-CHOP and the BR arm (94\% vs 93\% and 40\% vs $51 \%$, respectively). Number of deaths and the proportion of patients with progressive or relapsed disease were also comparable in both arms. Differences could be observed in terms of toxicity. Here, BR showed a more favorable profile, only $12 \%$ of patients developing grade III/IV leukocytopenia compared with $41 \%$ in the R-CHOP arm. Consequently, infectious complications were observed less frequently in the BR arm. ${ }^{25}$ Although final conclusions cannot be drawn yet because follow-up is still too short, results are promising and BR might challenge R-CHOP as a standard regimen for patients with indolent lymphoma in the coming years.

Currently, ongoing trials aim to further optimize first-line treatment of patients with advanced indolent lymphoma, for example by evaluating the role of high-dose chemotherapy after rituximab-containing induction therapy. In patients with early-stage FL who are usually treated by radiation only, a trial conducted by the GLSG aims at improving outcome of patients by administration of four weekly doses of rituximab as induction therapy prior to involved-field radiotherapy (IF-RT).
Rituximab-containing salvage regimens as well as rituximab maintenance therapy could also be shown to improve outcome of patients. Van Oers and colleagues conducted a trial including 465 patients with refractory or relapsed FL. Patients were randomized twice. The first randomization assigned patients to either an induction therapy with R-CHOP or with CHOP alone. Those patients who achieved PR or better were then randomized to either maintenance with rituximab every 3 months for a maximum of 2 years or observation. Rituximab-containing induction therapy as well as rituximab maintenance led to a superior outcome than conventional induction chemotherapy and observation, respectively.

After completion of induction therapy, 334 patients were eligible for randomization between rituximab maintenance and observation. With a median follow-up of 33.3 months from this second randomization, patients receiving rituximab maintenance had a median PFS of 51.5 months which was significantly longer than the median PFS of 14.9 months achieved in the observation group ( $p<0.001)$. OS was also significantly improved in the group receiving rituximab maintenance, with a 3 -year OS rate of $85.1 \%$ compared with $77.1 \%$ in the observation group $(p=0.011) .{ }^{26}$ Similar results were reported by other groups. The GLSG randomly assigned relapsed and refractory FL and MCL patients to either fludarabine/cyclophosphamide/mitoxantrone 
(FCM) or R-FCM. In addition, one group receiving rituximab maintenance and one group no further treatment. With a median observation time of 26 months, response duration in patients receiving rituximab maintenance was significantly longer, with a median duration not reached compared with 17 months in patients without maintenance $(\mathrm{p}<0.001) .{ }^{27}$

In contrast to maintenance after salvage treatment in relapsed patients, rituximab maintenance after primary treatment cannot be considered standard yet. A benefit remains to be proven in randomized trials. However, results of a phase II nonrandomized trial including NHL patients with mainly follicular histology are promising. Here, rituximab maintenance therapy after rituximab single-agent first-line therapy improved PFS compared with previous trials that had tested rituximab singleagent activity without subsequent maintenance therapy. ${ }^{28}$

Due to its high incidence, most patients included in clinical trials for indolent lymphoma are of FL subtype. Therefore, results of trials mainly represent efficacy of treatment protocols in FL. However, subgroup analyses and studies evaluating patients with MCL, chronic lymphocytic leukemia (CLL) or nodular lymphocyte-predominant Hodgkin lymphoma (NLPHL) revealed an improved outcome in these entities by the implementation of rituximab. ${ }^{29-32}$ In CLL, the combination of fludarabine, cyclophosphamide and rituximab (FCR) has become standard of care. In the ongoing randomized CLL10 trial conducted by the German CLL Study Group (DCLLSG), this standard is being compared with BR, which had been shown to have promising activity in previous non-randomized trials.

In summary, rituximab has become an indispensable part of the treatment for indolent NHL. This holds true for first-line as well as for salvage and maintenance therapy (Table 2).

\section{Clinical trials with rituximab in aggressive NHL}

Lymphoma subtypes such as DLBCL, anaplastic large cell lymphoma (ALCL) and Burkitt lymphoma belong to the group of aggressive NHL. Among those, DLBCL is most frequently diagnosed, with an incidence of about 3 to 4/100,000 persons/year. ${ }^{33}$ Since most DLBCL cells express CD20, they are a promising target for rituximab.

After phase II trials had shown safety and activity of rituximab in combination with conventional chemotherapy, several groups conducted controlled randomized trials directly comparing R-chemotherapy and chemotherapy alone in DLBCL patients. ${ }^{34}$ In these trials patients receiving R-chemotherapy had a significantly superior outcome.

In 2006 Pfreundschuh and colleagues published results from a trial including 824 patients aged 18 to 60 with good prognosis DLCBL. Patients were randomly assigned to either 6 cycles of CHOP-like chemotherapy supplemented by rituximab or 6 cycles of CHOP-like chemotherapy alone. Bulky and extranodal sites involved were irradiated. Addition

Table I Impact of rituximab on the outcome of indolent lymphoma in different indications

\begin{tabular}{|c|c|c|c|}
\hline & Regimens compared & $\begin{array}{l}\text { Improved outcome by } \\
\text { administration of rituximab? }\end{array}$ & References \\
\hline Conventional first-line therapy & $\begin{array}{l}\text { Conventional chemotherapy } \\
\text { vs } \\
\text { conventional chemotherapy } \\
\text { supplemented by rituximab }\end{array}$ & yes & $20,21,22$ \\
\hline $\begin{array}{l}\text { R-maintenance after conventional } \\
\text { first-line therapy }\end{array}$ & $\begin{array}{l}\text { Results of randomized trials are } \\
\text { pending }\end{array}$ & $\begin{array}{l}\text { Not yet proven in randomized } \\
\text { trials }\end{array}$ & 27 \\
\hline Conventional second-line therapy & $\begin{array}{l}\text { Conventional chemotherapy } \\
\text { vs } \\
\text { conventional chemotherapy } \\
\text { supplemented by rituximab }\end{array}$ & yes & 25,46 \\
\hline $\begin{array}{l}\text { R-maintenance after conventional } \\
\text { second-line therapy }\end{array}$ & $\begin{array}{l}\text { Rituximab maintenance } \\
\text { vs } \\
\text { observation }\end{array}$ & yes & 25,26 \\
\hline $\begin{array}{l}\text { High-dose chemotherapy as } \\
\text { second-line therapy }\end{array}$ & $\begin{array}{l}\text { Salvage regimen without rituximab } \\
\text { vs } \\
\text { rituximab-containing salvage regimen }\end{array}$ & yes & 47 \\
\hline $\begin{array}{l}\text { R-maintenance after high-dose } \\
\text { chemotherapy as second-line } \\
\text { therapy }\end{array}$ & $\begin{array}{l}\text { Results of randomized trials are not } \\
\text { available }\end{array}$ & $\begin{array}{l}\text { Not yet proven in randomized } \\
\text { trials }\end{array}$ & \\
\hline
\end{tabular}


of rituximab significantly improved the results. Three-year EFS was 59\% in patients who received chemotherapy alone but $79 \%$ in patients who also received rituximab $(p=0.0001)$. Patients receiving rituximab-containing treatment also had a superior OS, 93\% being alive after 3 years compared with $84 \%$ in the chemotherapy-alone group $(p=0.0001){ }^{35}$

The Groupe d'Etude des Lymphomes de 1'Adulte (GELA) randomly assigned 399 DLBCL patients aged 60 to 80 to either receive 8 cycles of CHOP or 8 cycles of R-CHOP. Response rate was significantly higher in patients receiving rituximab-containing treatment, $76 \%$ of them achieving $\mathrm{CR}$ or $\mathrm{CRu}$ (CR unconfirmed). In contrast, only $63 \%$ of patients in the CHOP alone arm achieved $\mathrm{CR} / \mathrm{CRu}$ $(p=0.005)$. With a median follow-up of 2 years, EFS and OS were also significantly improved in the R-CHOP arm, with $70 \%$ of the R-CHOP-treated patients alive compared with $57 \%$ of patients in the CHOP-alone arm $(\mathrm{p}<0.001$ and $\mathrm{p}=0.007$, respectively). ${ }^{36}$

In elderly patients with aggressive lymphoma, superiority of CHOP-14 in comparison with CHOP-21 had been shown in a trial by the German High-Grade Non-Hodgkin's Lymphoma Study Group (DSHNHL). ${ }^{37}$ A follow-up trial in patients over 60 years diagnosed with aggressive CD20positive B cell NHL compared 6 or 8 cycles of CHOP-14 with or without rituximab. Patients treated with 6 cycles of R-CHOP-14 had a better outcome than patients treated with 8 cycles of R-CHOP-14, 6 cycles of CHOP-14 or 8 cycles of CHOP-14, respectively. Three-year EFS was $66.5 \%$ in the group receiving 6 cycles of $\mathrm{R}-\mathrm{CHOP}-14$ arm compared with $63.1 \%, 47.2 \%$ and $53.0 \%$ in the groups receiving 8 cycles of R-CHOP-14, 6 cycles of CHOP-14 and 8 cycles of CHOP-14, respectively. Three-year OS was also best in patients treated with 6 cycles of R-CHOP-14. Based on the data of this trial, 6 cycles of R-CHOP-14 should be the preferred treatment in elderly patients with aggressive CD20-positive B cell NHL. Administration of R-chemotherapy beyond 6 cycles does not further improve patient outcome. ${ }^{38} \mathrm{~A}$ trial directly comparing R-CHOP14 and R-CHOP21 is currently being conducted by the GELA.

The value of rituximab maintenance in DLBCL is not fully defined yet. Results from a randomized trial including 415 patients that were published by Habermann and colleagues in 2006 indicated a beneficial effect for rituximab maintenance in those patients who were treated with a first-line regimen not containing rituximab but not for those who already received rituximab-containing primary treatment. In this study, rituximab maintenance was administered 4 times at 6-month intervals. ${ }^{39}$
In an ongoing trial rituximab maintenance every 8 weeks for a total of 2 years is being evaluated in patients who previously had received a rituximab-containing induction regimen. The trial has not yet finished recruitment and results are pending.

In relapsed CD20-positive aggressive B cell NHL, addition of rituximab to salvage chemotherapy could also be shown to improve response rates and outcome. In a randomized trial, 239 patients receiving salvage chemotherapy alone or supplemented with rituximab prior to high-dose chemotherapy and autologous stem-cell transplantation were included. Response rate was significantly better in the group receiving the rituximab-containing induction regimen, 75\% of patients responding compared to $54 \%$ in the chemotherapyalone group $(\mathrm{p}=0.01)$. With a median follow-up of 2 years, failure-free survival and PFS were longer in patients receiving rituximab (50\% and 52\% in the R-chemotherapy group vs $24 \%$ and $31 \%$ in the chemotherapy-alone group, $\mathrm{p}<0.001$ and $\mathrm{p}<0.002$, respectively). In Cox regression analysis, OS could also be shown to be superior in patients treated with the rituximab-containing scheme. ${ }^{40}$

In conclusion, rituximab has become an essential part in first-line as well as in salvage treatment of CD20-positive aggressive NHL. The value of rituximab in maintenance therapy cannot yet be fully defined (Table 2).

\section{Safety, tolerability and quality of life}

Generally, administration of rituximab is safe and well tolerated. In most patients treatment can be conducted in an outpatient setting and no hospitalization is required. Most infusion-related reactions occur during the first administration. Reactions such as fever, urticaria, hypotension and bronchospasm due to cytokine release are the adverse events most commonly observed. Since these reactions can become fatal, an adequate premedication should be applied and reanimation equipment should be within reach. After the first infusion the risk of cytokine release decreases markedly. ${ }^{41}$ Interstitial pneumonitis is a rare but potentially fatal adverse effect associated with rituximab. ${ }^{42,43}$ Awareness of this side effect is important since early treatment with glucocorticoids, mostly supplemented by antibiotics, leads to a full recovery in many patients.

The patient's quality of life during treatment with rituximab does not seem to be impaired, which is understandble because rituximab does not cause additional toxicity when used in combination with conventional chemotherapy, with the exception of a higher rate of leukocytopenia. ${ }^{44}$ To evaluate the quality of life in patients receiving rituximab 
Table 2 Impact of rituximab on the outcome of aggressive lymphoma in different indications

\begin{tabular}{|c|c|c|c|}
\hline & Regimens compared & $\begin{array}{l}\text { Improved outcome by } \\
\text { administration of rituximab? }\end{array}$ & References \\
\hline Conventional first-line therapy & $\begin{array}{l}\text { Conventional chemotherapy } \\
\text { vs } \\
\text { conventional chemotherapy supplemented } \\
\text { by rituximab }\end{array}$ & Yes & 34,35 \\
\hline $\begin{array}{l}\text { R-maintenance after conventional } \\
\text { first-line therapy }\end{array}$ & $\begin{array}{l}\text { Rituximab maintenance } \\
\text { vs } \\
\text { observation }\end{array}$ & $\begin{array}{l}\text { Variable; benefit depending on } \\
\text { therapy prior to R-maintenance }\end{array}$ & 38 \\
\hline $\begin{array}{l}\text { High-dose chemotherapy as } \\
\text { second-line therapy }\end{array}$ & $\begin{array}{l}\text { Salvage regimen without rituximab } \\
\text { vs } \\
\text { rituximab-containing salvage regimen }\end{array}$ & Yes & 39 \\
\hline $\begin{array}{l}\text { R-maintenance after high-dose } \\
\text { chemotherapy as second-line therapy }\end{array}$ & $\begin{array}{l}\text { Rituximab maintenance } \\
\text { vs } \\
\text { observation }\end{array}$ & $\begin{array}{l}\text { Not yet clear; trial is currently } \\
\text { recruiting }\end{array}$ & $\begin{array}{l}\text { Clinical trials. } \\
\text { gov Identifier: } \\
\text { NCT00078949 }\end{array}$ \\
\hline
\end{tabular}

maintenance, Witzens-Harig and colleagues conducted a prospective randomized trial. Patients with different subtypes of CD20-positive NHL were randomly assigned to either rituximab maintenance every 3 months for a total of 2 years or observation. Patients were handed out a set of questionnaires to complete. Several dimensions defining quality of life such as mobility, self-care, daily activities, pain and anxiety could be recorded on the questionnaires. With a total of 91 patients eligible for evaluation, no significant differences between groups could be detected, indicating that rituximab maintenance does not affect the quality of life. ${ }^{45}$

\section{Conclusions}

In the past decade rituximab has become an essential part of the treatment of CD20-positive lymphoma. Addition of rituximab to conventional chemotherapy has significantly improved patient outcome, which holds true for first-line as well as salvage therapy. The value of rituximab in maintenance therapy is still under investigation and not fully defined yet. Since application of rituximab is commonly well tolerated and side effects are mostly mild, quality of life does not seem to be impaired in patients receiving the antibody. Thus, in the future the use of rituximab or possible follow-up products will probably be expanded to even more indications than at present. Various trials not only in the field of lymphatic malignancies but also in patients with autoimmune disorders such as rheumatoid arthritis, idiopathic thrombocytopenic purpura, systemic lupus erythematosus and others are currently ongoing to generate data that will help to define new indications for the use anti-CD20 antibodies.

\section{Disclosures}

The authors declare no conflicts of interest.

\section{References}

1. Chan JK. The new World Health Organization classification of lymphomas: the past, the present and the future. Hematol Oncol. 2001;19(4):129-150.

2. Fisher RI, Gaynor ER, Dahlberg S, et al. Comparison of a standard regimen (CHOP) with three intensive chemotherapy regimens for advanced non-Hodgkin's lymphoma. N Engl J Med. 1993;328(14): 1002-1006.

3. Gallagher CJ, Gregory WM, Jones AE, et al. Follicular lymphoma: prognostic factors for response and survival. J Clin Oncol. 1986;4(10): $1470-1480$.

4. Ardeshna KM, Smith P, Norton A, et al. Long-term effect of a watch and wait policy versus immediate systemic treatment for asymptomatic advanced-stage non-Hodgkin lymphoma: a randomised controlled trial. Lancet. 16 2003;362(9383):516-522.

5. Horning SJ. Natural history of and therapy for the indolent nonHodgkin's lymphomas. Semin Oncol. 1993;20(5 Suppl 5):75-88.

6. Armitage JO, Weisenburger DD. New approach to classifying nonHodgkin's lymphomas: clinical features of the major histologic subtypes. Non-Hodgkin's Lymphoma Classification Project. J Clin Oncol. 1998;16(8):2780-2795.

7. Stashenko P, Nadler LM, Hardy R, Schlossman SF. Characterization of a human B lymphocyte-specific antigen. J Immunol. 1980;125(4): $1678-1685$

8. Reff ME, Carner K, Chambers KS, et al. Depletion of B cells in vivo by a chimeric mouse human monoclonal antibody to CD20. Blood. 1994;83(2):435-445.

9. Flieger D, Renoth S, Beier I, Sauerbruch T, Schmidt-Wolf I. Mechanism of cytotoxicity induced by chimeric mouse human monoclonal antibody IDEC-C2B8 in CD20-expressing lymphoma cell lines. Cell Immunol. 2000;204(1):55-63.

10. Demidem A, Lam T, Alas S, Hariharan K, Hanna N, Bonavida B. Chimeric anti-CD20 (IDEC-C2B8) monoclonal antibody sensitizes a B cell lymphoma cell line to cell killing by cytotoxic drugs. Cancer Biother Radiopharm. 1997;12(3):177-186.

11. Press OW, Appelbaum F, Ledbetter JA, et al. Monoclonal antibody 1F5 (anti-CD20) serotherapy of human B cell lymphomas. Blood. 1987; 69(2):584-591.

12. Maloney DG, Grillo-Lopez AJ, Bodkin DJ, et al. IDEC-C2B8: results of a phase I multiple-dose trial in patients with relapsed non-Hodgkin's lymphoma. J Clin Oncol. 1997;15(10):3266-3274. 
13. Maloney DG, Grillo-Lopez AJ, White CA, et al. IDEC-C2B8 (Rituximab) anti-CD20 monoclonal antibody therapy in patients with relapsed low-grade non-Hodgkin's lymphoma. Blood. 1997;90(6): 2188-2195.

14. McLaughlin P, Grillo-Lopez AJ, Link BK, et al. Rituximab chimeric anti-CD20 monoclonal antibody therapy for relapsed indolent lymphoma: half of patients respond to a four-dose treatment program. J Clin Oncol. 1998;16(8):2825-2833.

15. Berinstein NL, Grillo-Lopez AJ, White CA, et al. Association of serum Rituximab (IDEC-C2B8) concentration and anti-tumor response in the treatment of recurrent low-grade or follicular non-Hodgkin's lymphoma. Ann Oncol. 1998;9(9):995-1001.

16. Coiffier B, Lepretre S, Pedersen LM, et al. Safety and efficacy of ofatumumab, a fully human monoclonal anti-CD20 antibody, in patients with relapsed or refractory B-cell chronic lymphocytic leukemia: a phase 1-2 study. Blood. 2008;111(3):1094-1100.

17. Goldenberg DM, Rossi EA, Stein R, et al. Properties and structurefunction relationships of veltuzumab (hA20), a humanized anti-CD20 monoclonal antibody. Blood. 2009;113(5):1062-1070.

18. Hagenbeek A, Gadeberg O, Johnson P, et al. First clinical use of ofatumumab, a novel fully human anti-CD20 monoclonal antibody in relapsed or refractory follicular lymphoma: results of a phase $1 / 2$ trial. Blood. 2008;111(12):5486-5495.

19. Czuczman MS, Grillo-Lopez AJ, White CA, et al. Treatment of patients with low-grade B-cell lymphoma with the combination of chimeric antiCD20 monoclonal antibody and CHOP chemotherapy. J Clin Oncol. 1999;17(1):268-276.

20. Hiddemann W, Kneba M, Dreyling M, et al. Frontline therapy with rituximab added to the combination of cyclophosphamide, doxorubicin, vincristine, and prednisone (CHOP) significantly improves the outcome for patients with advanced-stage follicular lymphoma compared with therapy with $\mathrm{CHOP}$ alone: results of a prospective randomized study of the German Low-Grade Lymphoma Study Group. Blood. 2005;106(12):3725-3732.

21. Salles G, Mounier N, de Guibert S, et al. Rituximab combined with chemotherapy and interferon in follicular lymphoma patients: results of the GELA-GOELAMS FL2000 study. Blood. 2008;112(13): 4824-4831.

22. Marcus R, Imrie K, Solal-Celigny P, et al. Phase III study of R-CVP compared with cyclophosphamide, vincristine, and prednisone alone in patients with previously untreated advanced follicular lymphoma. J Clin Oncol. 2008;26(28):4579-4586.

23. Schulz H, Bohlius J, Skoetz N, et al. Chemotherapy plus Rituximab versus chemotherapy alone for B-cell non-Hodgkin's lymphoma. Cochrane Database Syst Rev. 2007(4):CD003805.

24. Rummel MJ, Al-Batran SE, Kim SZ, et al. Bendamustine plus rituximab is effective and has a favorable toxicity profile in the treatment of mantle cell and low-grade non-Hodgkin's lymphoma. J Clin Oncol. 2005; 23(15):3383-3389.

25. Rummel MJ, von Gruenhagen U, Niederle N, et al. Bendamustine plus Rituximab versus CHOP plus Rituximab in the first-line treatment of patients with indolent and mantle cell lymphomas - first interim results of a randomized phase III study of the StiL (Study Group Indolent Lymphomas, Germany). Blood (ASH Annual Meeting abstracts). 2007; 110(11):Abstract 385

26. van Oers MH, Klasa R, Marcus RE, et al. Rituximab maintenance improves clinical outcome of relapsed/resistant follicular non-Hodgkin lymphoma in patients both with and without rituximab during induction: results of a prospective randomized phase 3 intergroup trial. Blood. 2006; 108(10):3295-3301.

27. Forstpointner R, Unterhalt M, Dreyling M, et al. Maintenance therapy with rituximab leads to a significant prolongation of response duration after salvage therapy with a combination of rituximab, fludarabine, cyclophosphamide, and mitoxantrone (R-FCM) in patients with recurring and refractory follicular and mantle cell lymphomas: Results of a prospective randomized study of the German Low Grade Lymphoma Study Group (GLSG). Blood. 2006;108(13):4003-4008.
28. Hainsworth JD, Litchy S, Burris HA 3rd, et al. Rituximab as first-line and maintenance therapy for patients with indolent non-hodgkin's lymphoma. J Clin Oncol. 2002;20(20):4261-4267.

29. Lenz G, Dreyling M, Hoster E, et al. Immunochemotherapy with rituximab and cyclophosphamide, doxorubicin, vincristine, and prednisone significantly improves response and time to treatment failure, but not long-term outcome in patients with previously untreated mantle cell lymphoma: results of a prospective randomized trial of the German Low Grade Lymphoma Study Group (GLSG). J Clin Oncol. 2005;23(9):1984-1992.

30. Schulz H, Klein SK, Rehwald U, et al. Phase 2 study of a combined immunochemotherapy using rituximab and fludarabine in patients with chronic lymphocytic leukemia. Blood. 2002;100(9):3115-3120.

31. Rehwald U, Schulz H, Reiser M, et al. Treatment of relapsed CD20+ Hodgkin lymphoma with the monoclonal antibody rituximab is effective and well tolerated: results of a phase 2 trial of the German Hodgkin Lymphoma Study Group. Blood. 2003;101(2):420-424.

32. Schulz H, Rehwald U, Morschhauser F, et al. Rituximab in relapsed lymphocyte-predominant Hodgkin lymphoma: long-term results of a phase 2 trial by the German Hodgkin Lymphoma Study Group (GHSG). Blood. 2008;111(1):109-111.

33. Tilly H, Dreyling M. Diffuse large B-cell non-Hodgkin's lymphoma: ESMO clinical recommendations for diagnosis, treatment and followup. Ann Oncol. 2008;19 Supp1 2:ii67-ii69.

34. Vose JM, Link BK, Grossbard ML, et al. Phase II study of rituximab in combination with chop chemotherapy in patients with previously untreated, aggressive non-Hodgkin's lymphoma. J Clin Oncol. 2001; 19(2):389-397.

35. Pfreundschuh M, Trumper L, Osterborg A, et al. CHOP-like chemotherapy plus rituximab versus $\mathrm{CHOP}$-like chemotherapy alone in young patients with good-prognosis diffuse large-B-cell lymphoma: a randomised controlled trial by the MabThera International Trial (MInT) Group. Lancet Oncol. 2006;7(5):379-391.

36. Coiffier B, Lepage E, Briere J, et al. CHOP chemotherapy plus rituximab compared with $\mathrm{CHOP}$ alone in elderly patients with diffuse large-B-cell lymphoma. $N$ Engl J Med. 2002;346(4):235-242.

37. Pfreundschuh M, Trumper L, Kloess M, et al. Two-weekly or 3-weekly CHOP chemotherapy with or without etoposide for the treatment of elderly patients with aggressive lymphomas: results of the NHL-B2 trial of the DSHNHL. Blood. 2004;104(3):634-641.

38. Pfreundschuh M, Schubert J, Ziepert M, et al. Six versus eight cycles of bi-weekly CHOP-14 with or without rituximab in elderly patients with aggressive $\mathrm{CD} 20+\mathrm{B}$-cell lymphomas: a randomised controlled trial (RICOVER-60). Lancet Oncol. 2008;9(2):105-116.

39. Habermann TM, Weller EA, Morrison VA, et al. Rituximab-CHOP versus $\mathrm{CHOP}$ alone or with maintenance rituximab in older patients with diffuse large B-cell lymphoma. J Clin Oncol. 2006;24(19): 3121-3127.

40. Vellenga E, van Putten WL, van 't Veer MB, et al. Rituximab improves the treatment results of DHAP-VIM-DHAP and ASCT in relapsed/ progressive aggressive $\mathrm{CD} 20+\mathrm{NHL}$ : a prospective randomized $\mathrm{HOVON}$ trial. Blood. 2008;111(2):537-543.

41. Kimby E. Tolerability and safety of rituximab (MabThera). Cancer Treat Rev. 2005;31(6):456-473.

42. Wagner SA, Mehta AC, Laber DA. Rituximab-induced interstitial lung disease. Am J Hematol. 2007;82(10):916-919.

43. Liu X, Hong XN, Gu YJ, Wang BY, Luo ZG, Cao J. Interstitial pneumonitis during rituximab-containing chemotherapy for non-Hodgkin lymphoma. Leuk Lymphoma. 2008;49(9):1778-1783.

44. Schulz H, Bohlius JF, Trelle S, et al. Immunochemotherapy with rituximab and overall survival in patients with indolent or mantle cell lymphoma: a systematic review and meta-analysis. J Natl Cancer Inst. 2007;99(9):706-714

45. Witzens-Harig M, Reiz M, Heiss C, et al. Quality of life during maintenance therapy with the anti-CD20 antibody rituximab in patients with B cell non-Hodgkin's lymphoma: results of a prospective randomized controlled trial. Ann Hematol. 2008. 
46. Forstpointner R, Dreyling M, Repp R, et al. The addition of rituximab to a combination of fludarabine, cyclophosphamide, mitoxantrone (FCM) significantly increases the response rate and prolongs survival as compared with FCM alone in patients with relapsed and refractory follicular and mantle cell lymphomas: results of a prospective randomized study of the German Low-Grade Lymphoma Study Group. Blood. 2004;104(10):3064-3071.

47. Sebban C, Brice P, Delarue R, et al. Impact of rituximab and/or high-dose therapy with autotransplant at time of relapse in patients with follicular lymphoma: a GELA study. J Clin Oncol. 2008;26(21):3614-3620.

48. Herold M, Pasold R, Srock S, Neser S, Niederwieser D, Neubauer A, et al. Results of a prospective randomised open label phase iii study comparing rituximab plus mitoxantrone, chlorambucile, prednisolone chemotherapy (R-MCP) versus MCP alone in untreated advanced indolent non-Hodgkin's lymphoma (NHL) and mantle-cell-lymphoma (MCL). ASH Annual Meeting Abstracts. 2004;104:584.
49. Herold M, Haas A, Srock S, et al. Rituximab added to first-line mitoxantrone, chlorambucil, and prednisolone chemotherapy followed by interferon maintenance prolongs survival in patients with advanced follicular lymphoma: an East German Study Group Hematology and Oncology Study. J Clin Oncol. 2007;25(15):1986-1992.

50. Marcus R, Imrie K, Belch A, Cunningham D, Flores E, Catalano J, et al. CVP chemotherapy plus rituximab compared with CVP as firstline treatment for advanced follicular lymphoma. Blood. 2005;105: 1417-1423.

51. Rivas-Vera S, Baez E, Sobrevilla-Calvo P, Baltazar S, Tripp F, Vela J, et al. Is first line single agent rituximab the best treatment for indolent non-Hodgkin's lymphoma? Update of a multicentric study comparing rituximab vs CNOP vs rituximab plus CNOP. ASH Annual Meeting Abstracts 2005;106:2431.

\section{Publish your work in this journal}

OncoTargets and Therapy is an international, peer-reviewed, open access journal focusing on the pathological basis of all cancers, potential targets for therapy and treatment protocols employed to improve the management of cancer patients. The journal also focuses on the impact of management programs and new therapeutic agents and protocols on

\section{Dovepress}

patient perspectives such as quality of life, adherence and satisfaction. The manuscript management system is completely online and includes a very quick and fair peer-review system, which is all easy to use. Visit http://www.dovepress.com/testimonials.php to read real quotes from published authors. 